\title{
The treatment of Scope and Negation in Rosetta *
}

\author{
Elly van Munster \\ Philips Research Laboratorjes \\ P.O. Box 80.000, 5600 JA Eindhoven, The Netherlands
}

\section{Abstract}

This paper deals with the treatment of Scope and, in particular, Negation in Rosetta, a Machine Translation. system which translates between Dutch, Engligh and Spanish (Spanish only as a target language). It will be argued that the SOV versus SVO-character of a lan" guage has important consequences for its possibilities of reflecting scope through word ordex. A description will be given of the problems that arise translating from one type of language (the SOV-language Dutch) to the other (the SVO-languages English and Spanisi). The extent to which these problems can be solved will be outlined.

The paper has been divided into two main sections. In section one the phenomena are described linguistically, in section two a general idea is given of how these phenomena are dealt with in Rosetta.

\section{Linguistic phenumena}

\subsection{Fxpression of Scope}

Scope bearing elements can be divided into two classes: 1) NEG, containing both the adverbs niet(Dutch)/ not(English)/ no(Spanish) and quantifiers with molphologically incorporated negation, such as niets(D.)/ nothing(E.)/ nada(S.).

2) $\mathrm{NP}_{s}$ and adverbials containing a quantifier (from now on Q-elements) ${ }^{x}$, like veel kinderen(D.)/ many children(E.)/ michos wiños(S.), een vis(D.)/ a fish(E.)/ zrn pez(S.), vaak(D.)/ often(E.)/ muchas veces(S.), in sommige gevailen(D.)/ in some cases(E.)/ en algunos casos(S.), etc.

The question I am concerned with is how the scope order of $Q$-elements and NEG can be determined. In a Montague Grammar of the PTQ type, (1) would have two interpretations, one with Every man having wide scope and one with two women having wide scope /Montague 1.273/, /Dowty 1981/:

(1) Every man loves two women.

This paper condenses part of the content of the author's thesis, /Van Munster 1985/, extended with the results of further research. This research was partially sponsered by Nehem (Nederisndse Herstructureringsmaatschappij).

Ira this paper I lixnit myself to $Q-N P s_{\text {, }}$ although a parallel can be drawn between Q-NPs and $Q-A d v e r b i a l s$ (including $Q-P P_{s}$ ). Furthermore only extensionsl contexts are taken into consideration; intensional contexts are ignored.
However, the interpretation with Every man having wide scope is far more natural. Therefore, in accordance with Jackendoff's principle, /Jackendof $197 \%$ /, $\Upsilon$ make the simplifying assmmption that surfoce order in principle represents the most plausible scope order of Q elements and NEG in the following sense:

"A $Q / N E G$ element has scope over the $Q / N E G$ elerserts on its right and is itself isside the seope of the $Q / N E Q$ elements on its left".

Starting from this principle implies that other impor tant factors are not taken into consideration, such as:

- Intonation, which is not visible in a written text. Therefore sentences are considered wnder neutral stress and intonation.

- Context. Currently only isolated sentences are taken into consideration.

Essential for translation is that, even if we assume that (1) is ambignous between two scope readings, the sentence in the target language will have this same ambi guity as long as the Q-elements have the same surface order as in the source language. Furthermore, both sentences will have the same 'most plausible reading'.

\subsection{SVO versus SOV}

Rosetta translates between two types of languages, namely the SOV-type (Dutch) and the SVO-type (Spanish and English). This SOV. versus SVO. character has important consequences for the expression of scope. I claim that in both types of languages the position of NEG is as close to the left-hand side of the verb as possible: it oxly precedes possible $Q$ elements that are within the scope of NEG / Van Munster 1985/.

Consider the following scheme:

$\begin{array}{llll}\text { Dutch: } & \text { S } & \text { O-(O) } & \text { NEG-V } \\ \text { English/Spanish: } & \text { S } & \text { NEG-V } & \text { O-(O) }\end{array}$

In an SOV-language the verb (in basic position) is in sentence-final position, while in an SVO-language the verb is in second position. Consequently, in an SVO. language only two elements (one in subject position and one in 'shift-position', i.e. the position to the lett of the subject) ${ }^{2}$ can precede NEG; the objects are to the right of $\mathrm{NEG}$ in basic position. In an SOV-language like Dutch, however, the objects are to the left of $\mathrm{NEG}$ in basic position. In principle there is no restriction to the number of elements that can appear to the left of NEG.

In general it can be said that, especially if the sentence 
contains a IVEG, an SOV-language is more 'suited' to express scope through word order than is an SVO. language.

This basic difference between Dutch and Spanish/English can cause problems when translating from one tyype of language into the other. Consider e.g. (2), where (2)a cannot be translated into (2)b since the relative order of $\mathrm{NEG}$ and the $\mathrm{Q}-\mathrm{NP}$ is not the same:

(2) a De kinderen aten veel snoepjes niet op. "rhe-children-ate-many-aweets-not"

b The children didn't eat many sweets.

In the Finglish seratence the object has to be topicalized in oriex to get the correct scope relations:

(y) c Many sweets the children didn't eat.

\section{Subdivision of Quantifiers}

I. argus that the following subdivision of NPB can be made:

1A) Q JVPs aensitive to scope, i.e. the surface order of $Q_{-N P}$ and $N E G$ is crucial for the interpretation. (Outch: iemand ('everybody'), een $N$ ('a N'), veel $N$ ('many $N$ '), alle $N$ ('all N'), twee $N$ ('two N'); English: many $N$, three; Spanish: muchos ('many'), dos $N$ ("two N'), etr...).

E.g. (3) a does not mean the same as (3)b:

(3) No Niet veel mensen houden van vis.

'Not-many-people-like-fish'

b Veel mensen houden niet van vis.

'Many-people-like-not-fish'

1B) Q INPs not sensitive to scope, i.e. the surfice order of Q-NPs and NEG is not crucial for the interpretration; these NPs always have wide scope, irrespective of their position. (e.g. sommige $N$ ('some'), most $N$, alguien ('someone'), something, etc.) Since these NPs do contain a quantifier, however, there is a strong preference for a surface order which reflects the scope. Therefore, (4)b is a much more natural word order than (4)a, although both gentences have in fact the same meaning. (NB. For some speakers (4)a is even out).

\section{(4) a Niemand gelooft sommige opmerkingen. 'Nobody-believes-some-remarks' \\ b Sommige opmerkingen gelooft niemand. 'Some-remarks-believes-nobody'}

2) deftrite NPg (e.g. Jan ('John'), het boek ('the book'), the many linguists, etc.). Surface order is irrelevant for scope-interpretation. If in (4)a and (4)b

\footnotetext{
'Another term would be 'topicalistion-position'. How. ever, thais term cax cause confusion since in Roset ta a discinction is made between 'Bcope-shift' (treated in this paper; the sentence still has a neutral intonation), and 'topicalization" (th:- sentence has a non-neutral intonation; not the surface crder but the original position of the topicalined Quelement reffects the scope) Both types of shift go to shift-position Scopenshift is a transformation, Topicalization a rule. (lox these terms see section 2.1).
}

sommige is replaced by the definite deze, (a) and (b) not only have the same meaning but there is no difo ference in naturalness either. Definite NPs have the feature $[-\mathrm{Q}]$.

$1 A$ and $1 \mathrm{~B}$ together are the NPs traditionally called quantifiers. I will indicate the two types with resp. the features $[+S]$ and $[-S]$.

Note that the subdivision of Q-NPs is language specific, e.g. iemand in Dutch is scope-sexusitive, while the Spanish and English equivalents (resp. alguies and someone) are not.

Spanish and English seem to have much nore [-\$] elew ments than Dutch does, which, as I claim, relates to the fact that they are less suited to express scops through word order (see section 1.2).

\subsection{Two approaches to scopes}

In TG-oriented theories a distinction is often made be tween different types of negation: S-negation and VI. negation (e.g./Jackendoff $1972 /$, / Lasnik 1972/, a.o.), with the special addition of 'TVP= and $V$ negation for Dutch (e.g./Hoekstra 1985/) ${ }^{3}$. To illustiace brielly what is meant by the different types of negation, let me give an example of each:

\section{(5) a Jan heeft geen boek gelezen. \\ 'John--has-no-book-read' \\ (S-negation)}

b Niet veel mensers hebben een boek gelezert. 'Not-many-people-have-a-book-read' (S-negation)

c lemand heeft niet yereisd. 'Somebody-has-not-travelled' (VP.negation)

d Veel mensen hebben geen boek gelezen. 'Many-people-have-no-book-read' (TVP-negation)

e Jan heeft veel mensen iets niet verield. ${ }^{4}$ 'John-has-many-people-something-not-told' (V-negation)

It is assumed that the constituents to the right of $\mathrm{NEG}_{\text {, }}$ including the verb, are within the scope of NEG. In (a) NEG follows the subject, but since $J_{a n}$ is definite, $S$ negation is equivalent to VP-negation: as a general iule the position of NEG is after a definite (unless the sentence is contrastive). Both (a) and (b), however, can be paraphrased by 'it is not the case that ...' which is a proof of S-negation /Jackendoff 1972/. In (c) NEG has scope over the VP containing an intransitive verb, in (d) over the VP containing a transitive verb plus direct object and in (e) merely over the transitive verb. In logical terms, however, these sentences merely differ in the relative scope ordex of $\mathrm{NEG}_{\mathrm{C}}$ and Q elements (i.e. of scope operators). In a semantic, Montague. like theory a verb (unless it is a modal) is not a scope

\footnotetext{
${ }^{3}$ For a treatment of scope-ambiguity in $\mathrm{TG}$-franework see /May 1977/.

In the sample sentences the perfect bexse is used since this renders a word order with the main vexb in basic, i.s. sentence final, position.
} 


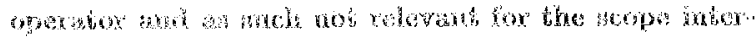

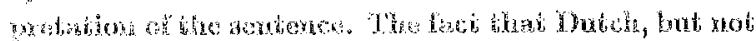

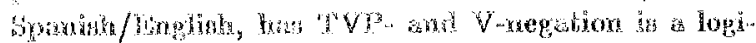

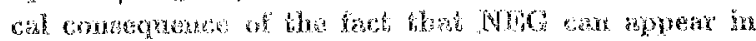

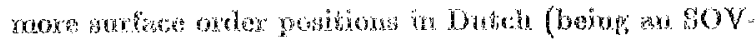
leverategol.

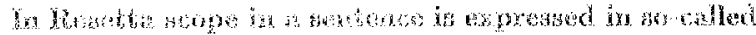

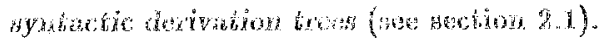

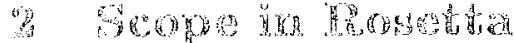

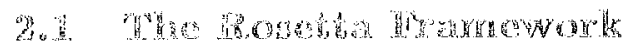

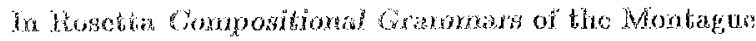

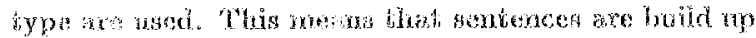

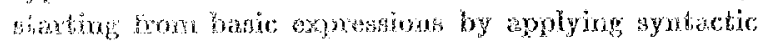

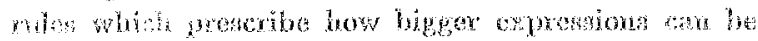

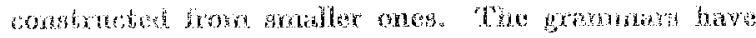

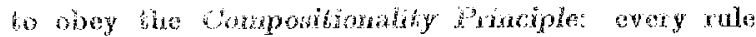

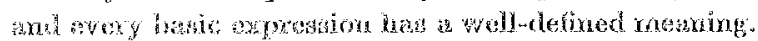

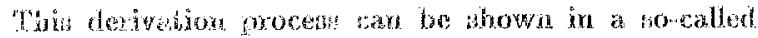

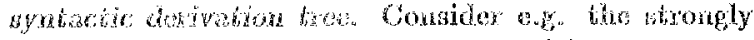

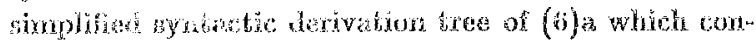
hating ixw

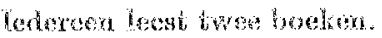

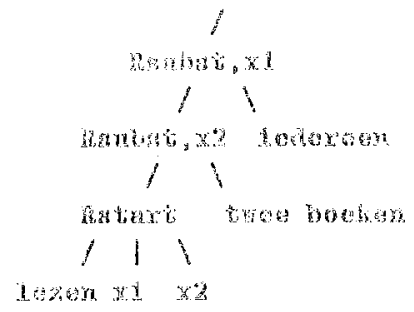

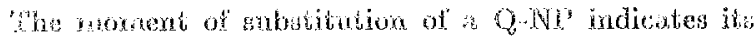

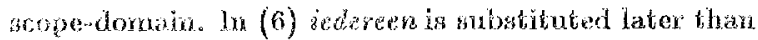

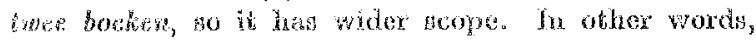
fon the most plansible reading of a montence we want ihe G-alements to be sabstibuted frown right to left in

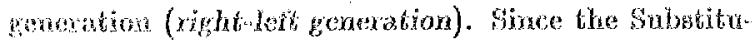
tion rales apply reely in principls, it is eswential that the condition on the applicability of Substitution- and Negation wates fore whis ordex, basically ix the following wys:

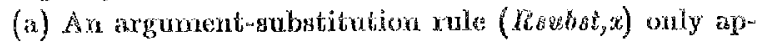
plies if there are no free variables (from now on VARa), to the right of the variabla to be mubstituted.

(b) A negation rule (Rneg) waly applies if there are no fres YARs to the right of the position where HEG in instertica.

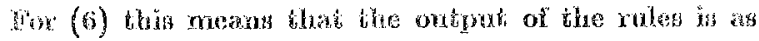
follow: (detisile omilted):

\begin{tabular}{|c|c|c|c|}
\hline & $x$ & $x y$ & let: \\
\hline$x:$ & $x$ & bwets booken & 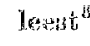 \\
\hline (40) & Iscoweers & Harea bostion & Ietsot \\
\hline
\end{tabular}

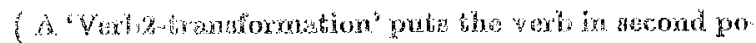

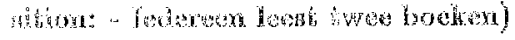

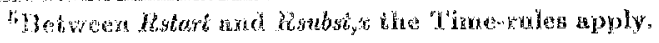

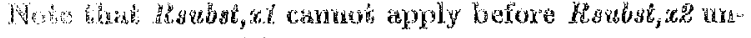

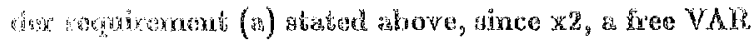

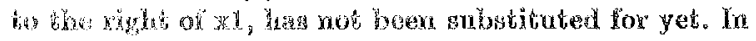

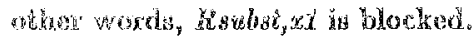

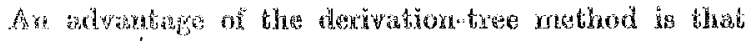

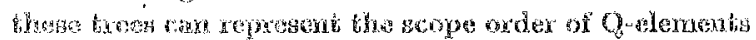

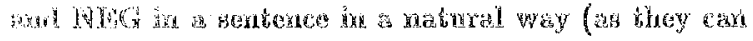

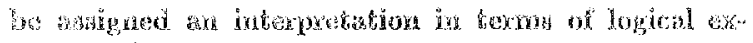
(1)

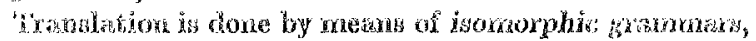

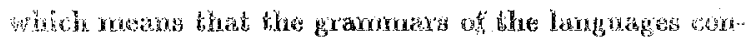

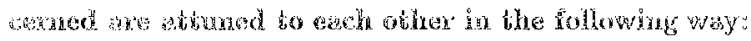

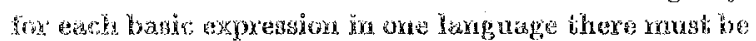
3i teasti one corresponding engression in the other lan-

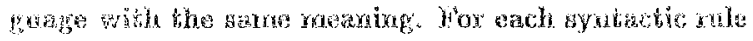

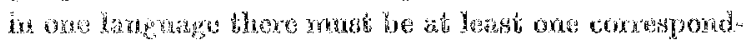

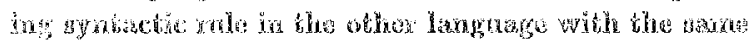

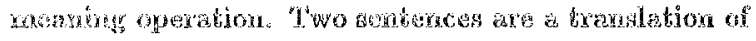

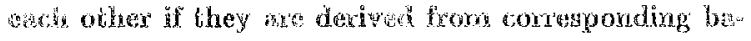
an: axpresatons by apglication of corresponding rules.

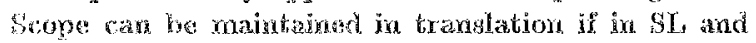

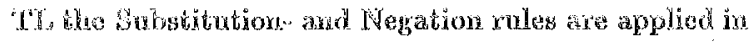
the sarke order. Consides How the English dexiwation

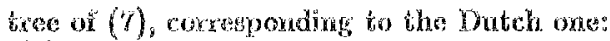

(7) Guerybody rends twa books.

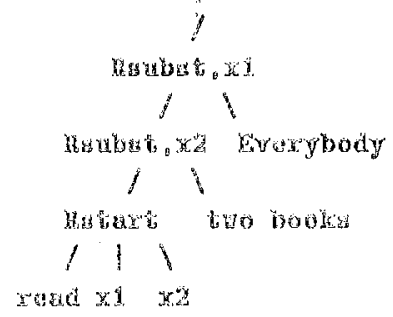

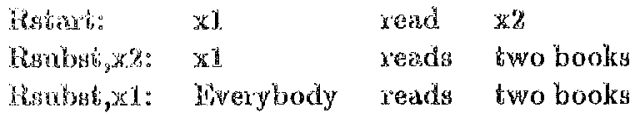

In this example there is nos problen making an isomor-

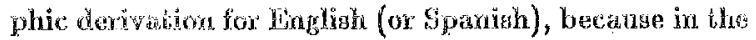
Dnglish trenclation the order of $\mathrm{Q}-\mathrm{NP}$ s is the seane as in 1 inusclo.

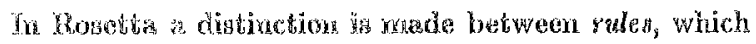

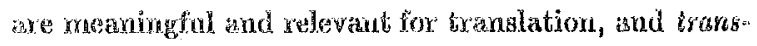
formations, which are langunge-specific, meaninglest and not relewant for translation. Since in the dexivation. twes mily the rales are represented, the corresponding treas hats awe the same geometry.

If the serutience conbing a raegation, this negation is

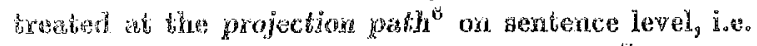

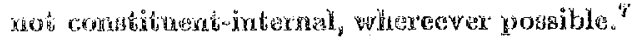

a.

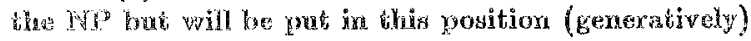
by andens of a trentomation. "fhe derivation tree sis:

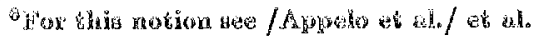

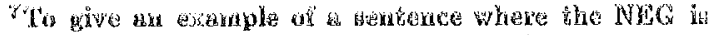

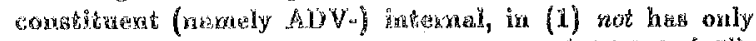

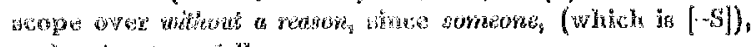

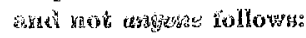

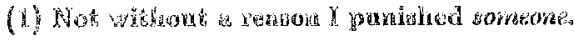


(8) a Niet iedere man loopt. Not--every-man-walks'

(a)

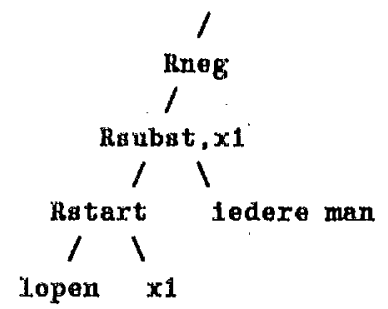

Rney applies at sentence-level. ${ }^{8}$

(For more theoretical details about the Rosetta framework sec: /Appelo 1987 et al./).

\subsection{Translating Scope}

Now, thare may be various reasons why the right-left substitution ordex causes problems, both within one language: and in translating from one language to another. In the subsections 1 and 2 the problems will be sketched, in 3 a general strategy for a solution in Rosetta will be given.

\subsubsection{Switch of arguments}

Problems within one language arise if the arguments have beon switched with respect to the order of the verbpattern (i.e. the argument structure of the verb), in order to express the correct scope relations in the sentence. Consider e.g. (9):

(9) Veel boeken leest iedereen.

'Many-books-reads-everybody'

Recall that in analysis the $Q$-arguments are substituted from left to right (cf. section 2.2), i.e. veel boeken ( $=$ $x 2)$ before iedereen $(=x 1)$. Now, the output of the generative rules is as follows:

$$
\begin{array}{llll}
\text { Rstirt: } & \text { x1 } & \text { x2 lezen } \\
\text { Rsubst,x1: } & \text { (blocked) } & &
\end{array}
$$

Rsubst,xt has to apply first but is blocked since there is a free $\operatorname{VAR}(\times 2)$ to the right.

This type of switch also occurs in translating from one language into the other, namely if the verb in the $T L$ has a different order of arguments than the verb in the SL. Consider e.g. the following verbpatterns:

Spanish: $\times 1$ dar $\times 2 \quad \times 3$

Dutch: $x 1 \quad \times 3 \quad \times 2$ geven

Again assuming that surface-order reflects scope order, (10)a and (10)b are not a correct translation of each other:

(10) a Jan geeft iedereen een boek. 'John-gives-everybody-a(='Bome')-book'

b Juan da un libro a todo el mundo. 'John-gives a('certain')-book-to-everybody'

The order of Q-NPB in the Spanish sentence has to be switched someliow.

${ }^{8} \mathrm{NEG}$ is introduced syncategorematically, although it could have been a basic expression an well.

\subsubsection{SOV/SVO problems}

If a sentence containing a NEG-element has to be translated from an SOV-language (like Dutch) into an SVO-language (like English/Spanish) problems may arise. Recall that the position of NEG is closely related to the position of the verb (cf. scheme in section 2). In principle no problems arise if NEG does not follow a Q-object in Dutch. (11)a and (12)a can simply be translated into (11)b and (12)b respectively:

(11) a Niet iedereen komt.

b Not everybody comes.

(12) a Veel mensen krijgen geen kado.

b Many people don't get a present.

However, as I explained in section 1.2, in Dutch (an SOV-language), NEG may occur to the right of a nontopicalized Q-object, as in (13):

(13) Wij stelden veel vragen niet.

'We-asked-many-questiong--not'

The corresponding syntactic derivation tree is as follows (since the Dutch and English trees are isomorphic, I only give the English or target one):

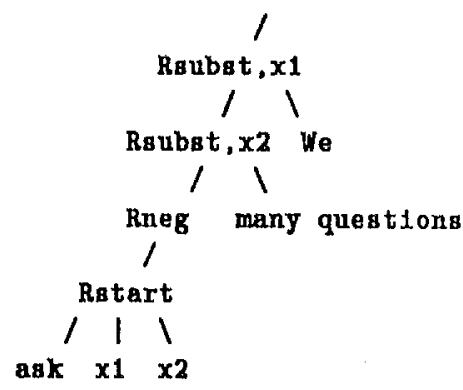

Schematically, the output of the rules is: Dutch:

$\begin{array}{lllll}\text { Rstart: } & \mathbf{x 1} & \mathbf{x 2} & & \text { stellen } \\ \text { Rneg: } & \mathbf{x 1} & \mathbf{x 2} & \text { niet } & \text { stellen } \\ \text { Rsubst,x2: } & \mathbf{x 1} & \text { veel vragen } & \text { niet } & \text { stellen } \\ \text { Rsubst,x1: } & \text { Wij } & \text { veel vragen } & \text { niet } & \text { stellen }\end{array}$

English:

$$
\begin{array}{ll}
\text { Rstart: } & \mathbf{x 1} \\
\text { Rneg: } & \text { (blocked) }
\end{array}
$$

Since $x 2$ is to the right of the verb (and thus of the NEG-position), Rneg is blocked. Note that this blocking is justified: without blocking the result of applying the English rules would be (14), which is not a correct translation of (13):

(14) We didn't ask many questions.

In other words, the wrong output is blocked but how can a correct translation be obtained? 


\subsection{Ceneral strategy for a solution}

In Rosettio two types of VARs are distinguished, nomely $[+Q]$ and $[-Q]$. Later on a Substitution rule can only substitute a $[+Q] N P$ for a $[+Q]$ VAR and a $[-Q] N P$ for a $[-Q]$ VAR. The following general strategy is followed:

In the shift-transformations, where VARs are shifted, $[+Q]$ VARs are shifted to shift-position under certain conditions. ${ }^{10}$ Since there is only one shift-position, only one VAR can be shifted at a time. These transformations precede the substitution-rules.

The shift-transformations can be subdivided into two cases:

1. A VAR is shifted over a $[+Q]$ VAR. For (9), (in which both arguments are $[+Q]$ ), this means that the shift-transformations render two surface orders of VARs:

$\begin{array}{llll}\text { (path i) } & x 1 & x 2 & \text { lezen } \\ \text { (path ii) } & \text { shift } / x 2 & x 1 & \text { lezen }\end{array}$

Later on, in the Substitution rules, only (ii) offers the correct input for a succesful application of Substitution rules, since VAR1 has to be substituted first (right-left generation). This type of shift is only meant to get the correct scope relations in a sentence, both when translating DutchDutch and Dutch-English/Spanish (see also note 2).

2. A VAR, is shifted over a $[-Q]$ VAR, under one of the following conditions:

A. There are two [+Q] VARs in the VP. The left one can shift over the [-Q] NP (subject).

b. There is one $[+Q]$ VAR in the VP; a negation. rule has to follow.

Although the conditions for both Dutch and Spanish/English are the same, the motivation for the shift over a $[-Q]$ NP in both types of langrages (i.e. SOV vs. SVO) is different:

For SVO-languages this shift is necessary in order to put a $[+Q]$ argument in a position to the left of NEG, i.e. to get the correct scope relations.

Consider again the ontput of the English rules for (13) $(V=$ "to asks):

Rule Output

Rstart:

Tshift:

x1

$\mathbf{x 1}$

shift/x2

$\mathrm{V} \quad \mathrm{x2}$

Rneg:

(blocked)

$$
\text { shift/x2 }
$$

$$
\text { many gs }
$$

many $q^{B}$

Rsu, $x 1$ :

many $q^{s}$ we not $V$

(Final result: - Many questions we did not ask)

${ }^{\circ} T$ This is the theoretical approach. In order to avoid many wrong paths in the derivation process, the implementation is slightly different: it is possible to extract information about the substituent from the dexivation tree and assign the correct $Q$-value to the VAR, before the generstive rules apply.

10rthe shift-transformations also shift WH-elements and relstives.
For Dutch, being an SOV-language, this type of shift is not necessary for scope, since all Q.NPs can precede NEG without shift (see section 1.2). However, this type of shift should be done anyway in order to generate both (15) a and (15)b as paraphrases of each other:

(15) a Jan geeft veel kinderen een snoepje.

'John-gives-many-children-s-sweet'

b Veel kinderen geeft Jan een snoepje.

'Many-children-gives-John-a-sweet'

(16) a and (16)b are also paraphrases of each other, but (1.7) $a$ and (17)b are not, considering condition $2 b^{11}$ :

(16) a Jan heeft veel boeken niet gelezen. 'John-has-many-books-not-read'

b Veel boeken heeft Jan niet gelezen. 'Many-books-has-John-not--read'

(17) a Jan heeft veel boeken gelezen. 'John-has-many-books-read'

b Veel boeken heeft Jan gelezen. 'Many-books-has-John-read'

\subsubsection{Coosening conditions}

As I explained earlier (section 1.3), in the SOV. language Dutch it is easier to express scope through word order than in English and Spanish, especially if the sentence contains a negation. In this section I will explain how the conditions (a) and (b), stated in sec. tion 2.1 can be loosened in order to be able to translate a Dutch serutence with more than two VARs to the left of NEG into Spanish/English.

In general it can be stated that $R$ neg and $R_{s u b s t}$ can apply freely even if there is a free VAR to the right, if this VAR is [-S]. Now there are two possibilities:

- The VAR is definite. The rules apply without restrictions. $^{12}$

- The VAR is a $[-\mathrm{S}]$ Q-VAR. In this case the surface order which reflects scope order is preferred (cf. (4)). Now, this preference will be handled in Rosetta by means of a so-called bonus system. Every output of a rule has a bonus 0 . Application of a rule can change this value. If there is more than one output, the bonus merely determines the order in which the output sentences appear.

\footnotetext{
${ }^{11}$ The reason behind these facts is that only an NP that is not the focus, can topicalize without changing the meaning (or the theme/rheme relations, /Suñer 1982/) of the sentence. However, since theory about focus is not ayailable yet in Rosetta, this is a way of either aroiding or making certain paraphrases of a sentence. In fact, (17)b is a correct paraphrase of (17) a in case veel boeken is not focus, but not in all cases. In short, under the conditions given only a paraphrase is given if the topicalized argument has to be a non-focus element, namely in case the negation is the focus ((16)b as paraphrase of (16)a) and in case another arga. ment as the one topicalized is focus ((15)b as paraphrase of (15)a).

${ }^{12} R-L$ generation in case of definites is merely done for efficiency, in order to avoid unwanted ambiguities.
} 
Let me illustrate this process with an example. Consider (18) and its Spanish derivation ( $\mathrm{V}=$ 'entender'):

(18) Ik begrijp iemand niet.

'I--understand-somebody-not'

\begin{tabular}{|c|c|c|c|c|c|c|}
\hline Rule & Output & & & & & bonus \\
\hline Rstart: & (i) $\times 1$ & & $\mathbf{V}$ & & $\times 2$ & 0 \\
\hline \multirow[t]{2}{*}{ Tahift: } & (i) $\times 1$ & & $\mathbf{V}$ & & $\mathbf{x} 2$ & 0 \\
\hline & (ii) $\mathrm{sh} / \mathrm{x} 2$ & & $x 1$ & & $\mathbf{v}$ & 0 \\
\hline \multirow[t]{2}{*}{ Rneg: } & (i) $\times 1$ & no & $\mathbf{V}$ & & $\mathbf{x} 2$ & -1 \\
\hline & (ii) $\mathrm{sh} / \mathrm{x} 2$ & & $\mathbf{x} 1$ & no & $\mathbf{v}$ & 0 \\
\hline \multirow[t]{2}{*}{ Rsu, x2: } & (i $) \times 1$ & no & $\mathbf{V}$ & & alg. & -1 \\
\hline & (ii) alg. & & $\mathbf{x} 1$ & no & $\mathbf{V}$ & 0 \\
\hline \multirow[t]{2}{*}{$R s u, x 1:$} & (i) yo & no & $\mathbf{V}$ & & alg. & -1 \\
\hline & (ii) alg. & & yo & no & $\mathbf{V}$ & 0 \\
\hline
\end{tabular}

Application of $R n e g$ with a free [-S] VAR to the right lowers the bonus with one. Consequently, the order of output sentences is:

(1) A alguien no entiendo. (output of path ii)

(2) No entiendo a alguien. ${ }^{1 s}$ (output of path i)

Furthermore, if the Dutch sentence has more than two $[+S]$ VA]Rs to the left of NEG, I tentatively propose to deviate from the conditions in the following way:

- Application of $R$ neg with a free [+S] VAR to the right lowers the bonus with 2 .

- Application of Rsubst.x with a free [+S] VAR to the right lowers the bonus with 3 .

In other words, a deviation in the order of NEG$[+\mathrm{S}] /[+\mathrm{S}]-\mathrm{NEG}$ is preferred to a deviation in the order of $[+S]$-elements mutually.

Now consider the Spanish derivation of (19) (isomorphic to the Dutch one):

(19) Twee kinderen aten veel snoepjes niet op.

'Two-children-ate-many-sweets-not'

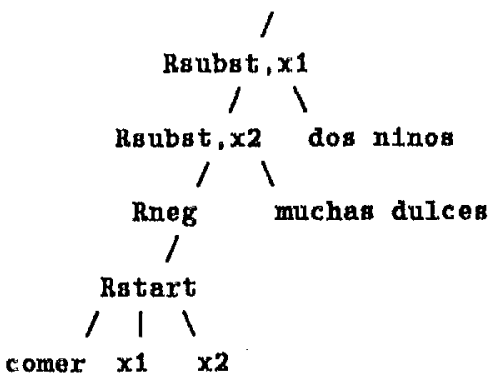

The output of the rules is ( $V=$ 'comer'):

\begin{tabular}{|c|c|c|c|c|c|c|}
\hline \multirow{3}{*}{$\begin{array}{l}\text { Rstart: } \\
\text { Tshift: }\end{array}$} & \multirow[b]{2}{*}{7} & & \multirow[b]{2}{*}{$\mathbf{V}$} & & \multirow[b]{2}{*}{$x^{2}$} & \multirow{2}{*}{$\begin{array}{l}\text { bonus } \\
0\end{array}$} \\
\hline & & & & & & \\
\hline & (i ) $\times 1$ & & $\mathbf{V}$ & & $\times 2$ & 0 \\
\hline & (ii) $\operatorname{sh} / \times 2$ & & $\mathbf{x 1}$ & & $\mathbf{V}$ & 0 \\
\hline Rneg: & (i) $\times 1$ & no & $\mathbf{V}$ & & $\mathbf{x 2}$ & -2 \\
\hline & (ii) $8 \mathrm{sh} / \mathrm{x} 2$ & & $\mathbf{x 1}$ & no & $\mathbf{v}$ & 0 \\
\hline Rsu, $\times 2$ : & (i) $\times 1$ & no & $\mathbf{V}$ & & m.d. & -2 \\
\hline & (ii) m.d. & no & $\mathbf{x l}$ & no & $\mathbf{V}$ & -3 \\
\hline Rsu, $x \mathbf{X I :}$ & $\begin{array}{l}\text { (i) d.n. } \\
\text { (ii) m.d. }\end{array}$ & $\begin{array}{l}\text { no } \\
\text { d.n. }\end{array}$ & $\begin{array}{l}\mathbf{V} \\
\text { no }\end{array}$ & $\mathbf{v}$ & m.d. & $\begin{array}{l}0 \\
-3\end{array}$ \\
\hline
\end{tabular}

\footnotetext{
${ }^{13}$ This sentence is marginal for many Spanish speakers. Compare Dutch, cf.(4), with surface order NEG + [-S] NP. For a fairly extended description of Spanish data w.r.t. negation see /Bosque 1980/.
}

The output sentences are:

(1) Dos niños no han comido muchos dulces. (path i)

(2) Muchos dulces dos niños no han comido. "(path ii)

Note that in neither of the output sentences the scope order is the same as in Dutch. The limit of scopetranslation has been reached.

\section{Conclusions}

In this paper I showed how in Rosetta translation prob lems with respect to scope can be solved to a certain extent by means of shift-transformations. Since a solution is not always possible if we want to strictly main* tain the surface order of Q-elements (and since on the other hand sentences are ambiguous anyway, particu* larly in SVO-languages like English and Spanish), rules which break scope-order prescriptions apply anyway but assign a lower bonus. This bonus has influence on the output order of sentences.

\section{Acknowledgements}

I would like to thank the members of the Rosetta team who gave their constructive commenta on earlier ver" sions of this paper.

\section{References}

Appelo, X. and Fellinger, C. and Landsbergen, J. (1987), Subgrammars, Rule Classes and Control in the Rosetta Translation System, In: ACL-Proceedings, 1-3 april 1987, pp.118-133, University of Copenhagen, Copenhagen, Denmark.

Bosque, I. (1980), Sobre la Negación, Ed. Cátedra, S.A. Madrid.

Dowty, D. and Wall, R. and Peters, S. (1981), Intsadtction to Montague Semantics, volume 11, D. Reidel Publishing Company, Dordrecht.

Hoekstra, H. (1985), The scope of Negation within a framework of an MT system, Doctoral Thesis, State University of Utrecht.

Jackendoff, R. (1972), Semantic Interpretation in Generative Grammar, M.I.T. Press, Cambridge, Mass.

Landsbergen, J. (1987), lsomorphic grammars and their use in the Rosetta translation system, In M. King (ed), Machine Translation today, pp.351-372. Edinburgh University Press, Edinburgh.

Lasnik, H. (1972), Analyses of Negation in English, M.I.T. Dissertation.

May, R. (1977), The Grammar of Quantification, M.I.T. Dissertation.

Munster, E. van, (1985), The treatment of Scope and Negation in ROSETTA: a Dutch-Spansish view, Doctoral Thesis, State University of Utrecht.

Suñer, M., (1982), Syntax and Semantics of Spanish Presentational Sentence-types, Georgetown University Press, Washington, D.C.

\footnotetext{
14An obvious consequeace of this approach is that in analysis the Spanish sentences will be ambiguous, too.
} 